\title{
Surgical Management of Solitary Nerve Sheath Tumors of the Cervical Spine: A Retrospective Case Analysis Based on Tumor Location and Extension
}

\author{
Junya ABE, ${ }^{1}$ Toshihiro TAKAMI, ${ }^{1}$ Kentaro NAITO, ${ }^{1}$ Toru YAMAGATA, ${ }^{2}$ \\ Hironori ARIMA, ${ }^{1}$ and Kenji OHATA ${ }^{1}$ \\ ${ }^{1}$ Department of Neurosurgery, Osaka City University Graduate School of Medicine, \\ Osaka, Osaka; \\ ${ }^{2}$ Department of Neurosurgery, Osaka City General Hospital, Osaka, Osaka
}

\begin{abstract}
Complete resection of spinal nerve sheath tumors (NSTs) does not always result in significant neurological deficit. The purpose of this retrospective case analysis was to discuss the optimal surgical strategy for spinal NST of the cervical spine. Twenty-four patients who underwent surgery for solitary cervical NST over the past decade were included in this retrospective study. Patients with neurofibromatosis or schwannomatosis were excluded. Seventeen of the 24 cases $(70.8 \%)$ showed extradural dumbbell extension, most frequently at the C1 or C2 vertebral level. Neurological condition was assessed using the modified McCormick functional schema and sensory pain scale. Total removal of the tumor was achieved in 20 of 24 cases (83.3\%). Staged surgery using combined anterior and posterior approaches was applied for 2 of 17 cases with extradural dumbbell extension. Tumor involvement with nerve root fibers critical for upper extremity function (C5-C8) was recognized in 6 of 24 cases (25.0\%), with complete resection in all 6 cases. Final assessment of neurological function revealed satisfactory or acceptable recovery in all 6 patients. Spinal NSTs with extradural dumbbell extension are a common condition in the cervical spine. Complete removal of spinal NST of the cervical spine may carry a risk of permanent neurological deficit, but such sequelae appeared to be the exception in the present case analysis. A radical and safe surgical strategy, including staged surgery combining anterior and posterior approaches, should be tailored to the individual case.
\end{abstract}

Key words: dumbbell tumors, nerve sheath tumors, neurofibroma, schwannoma, spinal cord tumors

\section{Introduction}

The definition of spinal nerve sheath tumor (NST) is often confused by the different categories of tumors such as schwannomas, neurofibromas, neuromas, or neurinomas. ${ }^{1-3)}$ Schwannomas are generally agreed to originate from a Schwann cell progenitor and arise from a single nerve fascicle of a dorsal spinal nerve root. However, the origin of neurofibroma remains less clear. The size of spinal NST varies from an intradural tumor involving a single rootlet to an extradural tumor involving the entire nerve, including motor and sensory roots. Surgical strategies for spinal NST are not straightforward. Resecting tumor-involved nerve root fibers does not always result in significant neurological deficit, even if the

Received April 25, 2014; Accepted May 29, 2014 lesion is at the critical C5-C8 levels., ${ }^{4,5)}$ The extent of resection of tumor-involved nerve root fibers varies from a single rootlet in intradural tumors to an entire radix, including both sensory and motor fibers, in large, dumbbell-shaped tumors. The purpose of this retrospective study was to analyze surgical outcomes for consecutive patients with cervical solitary NSTs based on tumor location and extension, and to clarify the optimal surgical strategy.

\section{Materials and Methods}

A total of 24 patients (9 men, 15 women) who underwent surgery for solitary cervical NSTs over the past 10 years were included in this retrospective study. Patients with neurofibromatosis or schwannomatosis were excluded from the study. At the time of surgery, mean patient age was 51.3 years (range, 
23-77 years). All patients underwent comprehensive evaluation both before and after surgery. The neurological condition before and after surgery was assessed using the modified McCormick functional schema and sensory pain scale (Table 1$){ }^{6-8)}$ The mean duration of follow-up was 41.5 months (range, 1-111 months). Medical charts of all patients were reviewed retrospectively for spine level, tumor location, surgical findings, pathological diagnosis, and surgery-related outcome. Tumor location was

Table 1 Modified McCormick functional schema and sensory pain scale

\begin{tabular}{cl}
\hline Grade & \multicolumn{1}{c}{ Definition } \\
\hline 1 & $\begin{array}{l}\text { Neurologically normal; mild focal deficit not } \\
\text { significantly affecting limb function; mild } \\
\text { spasticity or reflex abnormality; normal gait }\end{array}$ \\
2 & $\begin{array}{l}\text { Presence of sensorimotor deficit affecting function } \\
\text { of the involved limb; still functions and ambulates } \\
\text { independently; mild gait difficulty }\end{array}$ \\
3 & $\begin{array}{l}\text { Presence of sensorimotor deficit affecting function } \\
\text { of the involved limb; still functions and ambulates } \\
\text { independently; moderate gait difficulty }\end{array}$ \\
4 & $\begin{array}{l}\text { More severe neurological deficit; requires cane/ } \\
\text { brace for ambulation or significant bilateral } \\
\text { upper-extremity impairment; may or may not } \\
\text { function independently }\end{array}$ \\
5 & $\begin{array}{l}\text { Severe deficit; requires wheelchair or cane/ } \\
\text { brace with bilateral upper-extremity impairment; } \\
\text { usually not independent }\end{array}$ \\
Grade & No symptoms \\
1 & Mild pain or dysesthesia, slightly impairing QOL \\
2 & Moderate pain or dysesthesia, fairly impairing \\
4 & $\begin{array}{l}\text { QOL } \\
\text { Severe pain or dysesthesia, significantly impairing } \\
\text { QOL }\end{array}$
\end{tabular}

QOL: quality of life. simply classified into the following three groups: intradural location of dorsal origin, intradural location of ventral origin, or extradural dumbbell extension. Seventeen of the 24 cases $(70.8 \%)$ showed extradural dumbbell extension.

\section{Statistical analysis}

Statistical analysis was performed using StatMate IV for Windows software (Atoms, Tokyo). The Wilcoxon signed-rank test was used to assess differences in modified McCormick functional schema and sensory pain scale scores between before and after surgery. Probability values $<0.05$ were considered significant.

\section{Statement of ethics}

The authors certify that all applicable institutional and governmental regulations concerning the ethical use of clinical data were adhered to for the present study. Our retrospective outcome analysis of spine surgery was approved by the ethics committee of Osaka City University Graduate School of Medicine.

\section{Results}

Total removal of the tumor was achieved in 20 of 24 cases $(83.3 \%)$. In the remaining four cases, partial or subtotal removal of the tumor was performed. No cases required re-operation because of tumor regrowth during the follow-up period. Surgical findings and outcomes of all patients are summarized based on spine level and tumor extension in Table 2.

\section{Surgical methods}

The surgical method was tailored to each individual case. Spinal NST showing an intradural location was resected via a posterior standard or unilateral

Table 2 Summary of surgical findings and outcomes

\begin{tabular}{|c|c|c|c|c|c|c|c|}
\hline \multirow{3}{*}{ Spine level } & \multirow{3}{*}{$\begin{array}{l}\text { Total no. } \\
\text { of cases }\end{array}$} & \multicolumn{3}{|c|}{ Tumor extension \& origin } & \multicolumn{3}{|c|}{ Tumor removal } \\
\hline & & \multicolumn{2}{|c|}{ Intradural location } & \multirow{2}{*}{$\begin{array}{l}\text { Extradural dumbbell } \\
\text { extension }\end{array}$} & \multirow{2}{*}{ Total } & \multirow{2}{*}{ Subtotal } & \multirow{2}{*}{ Partial } \\
\hline & & Dorsal origin & Ventral origin & & & & \\
\hline C1 & 3 & 0 & 1 & 2 & 3 & 0 & 0 \\
\hline C2 & 8 & 0 & 1 & 7 & 8 & 0 & 0 \\
\hline C3 & 5 & 0 & 0 & 5 & 2 & 1 & 2 \\
\hline $\mathrm{C} 4$ & 2 & 1 & 0 & 1 & 2 & 0 & 0 \\
\hline C5 & 2 & 0 & 1 & 1 & 2 & 0 & 0 \\
\hline C6 & 1 & 0 & 1 & 0 & 1 & 0 & 0 \\
\hline $\mathrm{C} 7$ & 2 & 2 & 0 & 0 & 2 & 0 & 0 \\
\hline C8 & 1 & 0 & 0 & 1 & 0 & 0 & 1 \\
\hline Total & 24 & 3 & 4 & 17 & 20 & 1 & 3 \\
\hline
\end{tabular}


approach with several modifications such as unilateral partial facetectomy or spinal cord rotation technique with resection of the dentate ligament. In cases with spinal NST showing an extradural dumbbell extension, particularly originating from the C1 or C2 level, exposure of the tumor along the surgical plane of the dural or perineural boundary was the key procedure required to accomplish radical and safe resection of the tumor. ${ }^{9)}$

To avoid postoperative instability, facetectomy was designed to involve less than $25 \%$ of each facet joint. Staged surgery using a combined anterior and posterior approach was applied in 2 of 17 cases with extradural dumbbell extension.

\section{Table 3 Summary of functional outcomes}

\begin{tabular}{crrrrrr}
\multicolumn{7}{c}{ Modified McCormick functional schema } \\
\hline \multirow{2}{*}{ Preop } & \multicolumn{7}{c}{ Postop } \\
\cline { 2 - 7 } & 12 & 0 & 0 & 0 & 0 & 12 \\
2 & 0 & 2 & 0 & 0 & 0 & 2 \\
3 & 2 & 4 & 0 & 0 & 0 & 6 \\
4 & 1 & 0 & 1 & 0 & 0 & 2 \\
5 & 0 & 2 & 0 & 0 & 0 & 2 \\
Total & 15 & 8 & 1 & 0 & 0 & 24 \\
\hline & Sensory pain scale & & \\
\hline Preop & & & Postop & & \\
\hline 1 & 1 & 2 & & 3 & 4 & Total \\
\hline 2 & 4 & & 1 & 0 & 0 & 3 \\
3 & 1 & 7 & & 0 & 0 & 10 \\
4 & 0 & 3 & 0 & 0 & 8 \\
Total & 7 & 17 & 0 & 0 & 24 \\
\hline
\end{tabular}

\section{Functional outcomes}

The final outcome was assessed at least 3 months after surgery, except in two cases. Overall analysis of modified McCormick functional schema scores between before and after surgery demonstrated that 10 cases were improved, 14 cases were stable, and no cases showed deterioration (Table 3). Mean modified McCormick functional schema score before surgery was 2.2 , improving significantly to 1.4 after surgery $(p<0.05)$. Overall analysis of the sensory pain scale demonstrated that 15 cases were improved, 8 cases were stable, and only 1 case was deteriorated (Table 3 ). The mean sensory pain scale before surgery was 2.5, improving significantly to 1.8 after surgery ( $p$ $<0.05$ ). Six patients underwent sacrifice of root fibers critical for upper extremity function (C5C8). Two patients (Cases 3 and 18) demonstrated partial loss of strength before surgery. Although 2 patients with NST of intradural dorsal origin (Cases 15 and 19) did not demonstrate any deterioration after surgery, 4 patients with NST of intradural ventral origin or extradural dumbbell extension (Cases 1, 3, 18, and 22) demonstrated significant deterioration early after surgery. Final assessment of neurological function revealed satisfactory or acceptable recovery in all 4 patients (Table 4).

\section{Illustrative Case}

\section{Case 22: Intradural ventral origin of $\mathbf{C 5}$}

A 68-year-old man presented with several years history of moderate dysesthesia of all fingers on both hands. Neurological examination revealed moderate sensory impairment of the left upper extremity and mild spastic gait. Assessment of neurological condition before surgery suggested Grade 1 on the modified McCormick functional schema and Grade 3 on the sensory pain scale. $\mathrm{T}_{2^{-}}$and enhanced $\mathrm{T}_{1}$-weighted magnetic resonance imaging (MRI) of

Table 4 Summary of six patients who underwent sacrifice of root fibers critical for upper extremity function (C5-C8)

\begin{tabular}{|c|c|c|c|c|c|c|c|c|c|}
\hline \multirow{2}{*}{ Case } & \multirow{2}{*}{ Age } & \multirow{2}{*}{ Sex } & \multirow{2}{*}{$\begin{array}{l}\text { Spine } \\
\text { level }\end{array}$} & \multirow{2}{*}{$\begin{array}{l}\text { Tumor extension } \\
\text { \& origin }\end{array}$} & \multirow{2}{*}{$\begin{array}{l}\text { Degree } \\
\text { of tumor } \\
\text { removal }\end{array}$} & \multirow{2}{*}{$\begin{array}{l}\text { Pathological } \\
\text { diagnosis }\end{array}$} & \multicolumn{3}{|c|}{ Motor deficit of upper extremity } \\
\hline & & & & & & & Preop & Early postop & Late postop \\
\hline 1 & 59 & M & C8 & Dumbbell & Partial & Neurofibroma & - & Mild & Recovery \\
\hline 3 & 56 & M & C5 & Dumbbell & Total & Schwannoma & Mild & Moderate & Mild \\
\hline 15 & 37 & $\mathrm{~F}$ & $\mathrm{C} 7$ & Intradural dorsal & Total & Schwannoma & - & - & - \\
\hline 18 & 77 & $\mathrm{~F}$ & C6 & Intradural ventral & Total & Schwannoma & Mild & Mild & Recovery \\
\hline 19 & 66 & $\mathrm{~F}$ & $\mathrm{C} 7$ & Intradural dorsal & Total & Schwannoma & - & - & - \\
\hline 22 & 68 & M & C5 & Intradural ventral & Total & Schwannoma & - & Moderate & Recovery \\
\hline
\end{tabular}



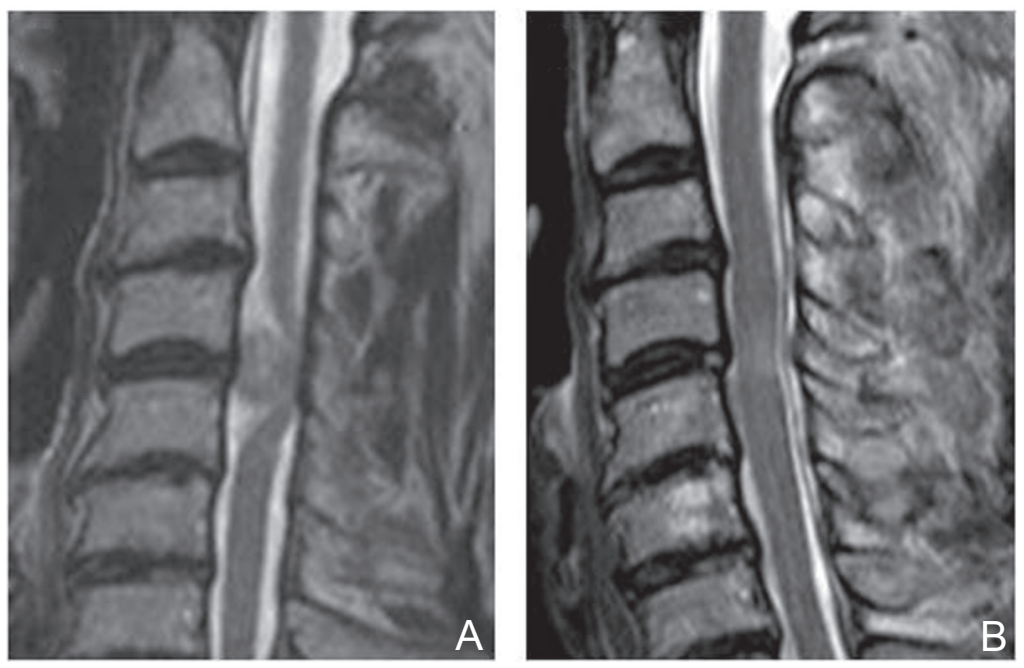

Fig. 1 Case 22. A: Preoperative $T_{2}$-weighted MRI of the cervical spine demonstrating intradural tumor at the $\mathrm{C} 4 / 5$ level with severe compression of the spinal cord. The tumor appears to be localized to the ventral side. $B$ : Postoperative $\mathrm{T}_{2}$-weighted MRI demonstrating complete removal of the tumor. MRI: magnetic resonance imaging.
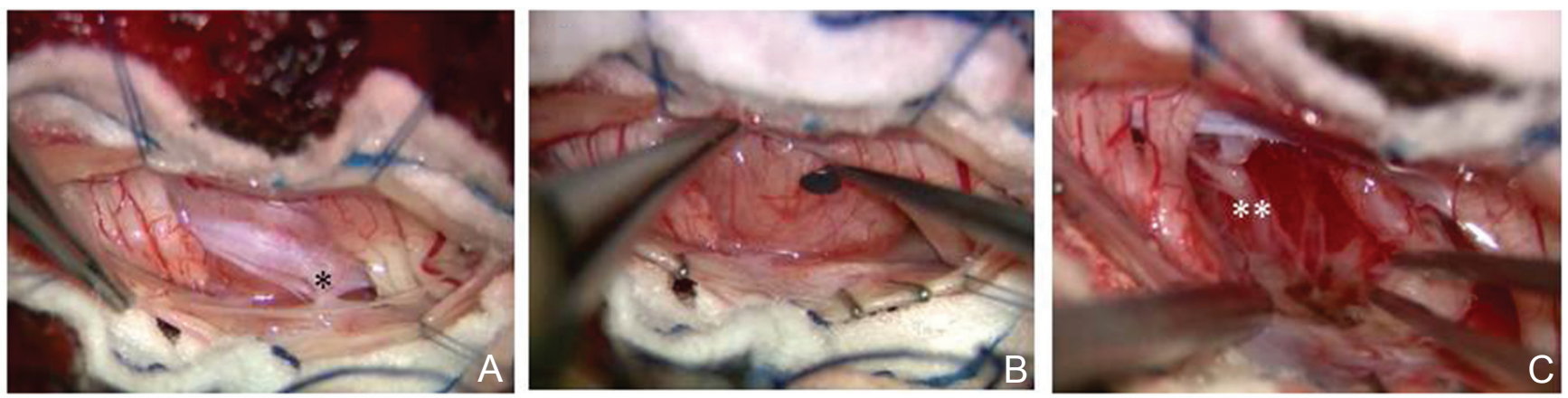

Fig. 2 Case 22. Intraoperative photographs showing the surgical steps of tumor removal. A: The tumor is completely localized in the ventral canal compressing the spinal cord dorsally. Please note the dentate ligament (*). B: After resecting the dentate ligament, the tumor is well exposed. C: The tumor is resected completely with the tumor-involved nerve root fibers of C5 after confirming a lack of response to electrical stimulation. Please note the proximal stump of the tumor $\left({ }^{*}\right)$.

the cervical spine revealed an intradural tumor at the C4/5 level with severe compression of the spinal cord (Fig. 1A). The tumor appeared to be localized to the ventral side.

At the time of surgery, intradural tumor was removed completely using a posterior unilateral approach to C4/5. The tumor was completely localized to the ventral side of the dentate ligament (Fig. 2A, B). The tumor was resected completely, along with the tumor-involved nerve root fibers of C5 after confirmation of no response to electrical stimulation (Fig. 2C).

The patient developed moderate deterioration of left C5 nerve motor function early after surgery, but this gradually improved, and he demonstrated complete recovery of left C5 motor function by 3 months postoperatively. $\mathrm{T}_{2}$ - and enhanced $\mathrm{T}_{1}$-weighted MRI obtained after surgery showed complete removal of the tumor (Fig. 1B). Assess- ment of neurological condition at the most recent follow-up suggested Grade 1 on the modified McCormick functional schema and Grade 1 on the sensory pain scale.

\section{Discussion}

Due to the long-term risk of tumor recurrence, our surgical concept for spinal NST is complete removal of the tumor with involved nerve root fibers. The surgical risk of neurological deficit after the resection of tumor-involved nerve root fibers remains controversial. Previously published data suggest that neurological deficit may occur at a frequency of $2.3-63 \%$, including permanent deficit. ${ }^{3-5,10,11)}$ An absolute consensus on this issue has yet to be reached. Several authors have argued that the spinal nerve roots giving origin to NSTs are frequently nonfunctional by the time of surgery, and the surgical 
risk is actually modest.,12-14) $\mathrm{Kim}$ et al. analyzed 86 surgically treated cases of spinal schwannoma, including 31 patients who underwent sacrifice of a root critical for function of the upper (C5-T1, 14 cases) or lower (L3-S1, 17 cases) extremities. ${ }^{4)}$ Only seven patients $(23 \%)$ developed detectable motor or sensory deficits postoperatively, and all deficits were no more severe than partial loss of strength or sensation. Lot and George described a case series of 57 patients with cervical neuromas with extradural components. ${ }^{15)}$ The mean rate of root preservation was $28 \%$, including $43.5 \%$ for schwannoma, $18 \%$ for neurofibroma, $44 \%$ for lower cervical neuroma (C4-C8), and $4.5 \%$ for upper cervical neuroma (C1C3). Worsening of preoperative neurological deficits was observed in only 2 patients. They insisted that intraoperative stimulation can help to decide whether the root may be divided without incurring postoperative deficit, if the root cannot be separated from the tumor, particularly among patients with neurofibromas. Celli analyzed a single institution series of 26 patients who underwent surgery for 27 spinal schwannomas or neurofibromas, removed together with functionally relevant nerve roots (C5-C8 or L3-S1). ${ }^{16)}$ He suggested that the incidence of radicular dysfunction after resection of a single eloquent nerve root with NST involvement is low, but warned that severe weakness is possible. He also proposed that the main risk factors are the pathological pattern of the tumor, the preoperative status of the involved nerve root, and the location of tumor growth. In the present study, sensory deficit early after the resection of tumor-involved nerve root fibers was not significant, although not elaborately examined, but final assessment of the sensory pain scale demonstrated satisfactory or acceptable recovery. On the other hand, motor deficit early after resection of C5-C8 nerve root fibers was significant, although such deficits demonstrated satisfactory or acceptable recovery late after surgery. Compensation of motor function after resection of C5-C8 nerve roots is not well understood. The anatomical or physiological characteristics of this spine level, including brachial plexus network, may be the key reason for the neurological compensation and functional recovery. Surgeons need to be aware that radical resection of spinal NST that extends into brachial plexus elements carries a high risk of significant postoperative dysfunction.

Intradural NSTs of the cervical spine can be resected using a posterior standard or unilateral approach. A key issue may be the surgery for dumbbellshaped NST. Our previous report demonstrated the surgical technique for spinal NST originating from the upper cervical spine (C1-C2), and suggested the importance of exposing the tumor along the surgical plane of the dural or peripheral boundary. ${ }^{9)}$ However, we believe that anterior access to the ventral spinal canal is desirable in selected cases at the C3-C7 spine level. Hakuba et al. demonstrated a surgical technique using combined anterior and lateral approaches to the anterior cervical spinal canal with fusion in cases of cervical dumbbellshaped tumors. ${ }^{17)}$ They insisted that any cervical dumbbell-shaped tumor below the C2 level can be removed via an anterolateral approach, as long as no more than three levels of the spine are involved. They also reported a case of giant dumbbell-shaped neurinoma in the spinal canal extending from the C3-C6 level and causing significant compression of the cord posteriorly. ${ }^{18)}$ McCormick presented his surgical experience of 12 patients with benign dumbbell tumor of the cervical spine. He used a single-stage modified posterior midline exposure with laminectomy and complete unilateral facetectomy, and achieved gross total resection of the tumor in 11 of 12 patients. ${ }^{19)}$ Lot and George demonstrated a case series of 57 patients with cervical neuroma showing extradural components who were treated using an antero or posterolateral approach. ${ }^{15)}$ They demonstrated the utility of the lateral approach of oblique corpectomy to permit resection of both the extra- and intradural components. Zhao and $\mathrm{Xu}$ demonstrated an extensive posterolateral approach to cervical spine dumbbell tumors involving total lateral mass resection and laminectomy. ${ }^{20}$ They concluded that their technique enables surgeons to reach the lateral most portion of cervical spine dumbbell tumors and also facilitates separation of the vertebral artery and resection of vertebral body encroachment of the tumor.

Jiang et al. analyzed 44 consecutive patients with cervical dumbbell tumor who were treated surgically, and detailed their own classification for cervical dumbbell tumors. ${ }^{21)}$ They stated that the recurrence rate decreases significantly after radical tumor resection, and revision surgeries are associated with more complications. Although complete removal of spinal NST may carry a surgical risk of significant, permanent deficit, such outcomes appeared exceptional in the present study. Complete removal of the tumor along with tumor-involved nerve root fibers may be acceptable, even in cases of the critical C5-C8 spinal level. Spinal NST with an intradural location was safely resected using a posterior standard or unilateral approach with several technical modifications. Staged surgery with combined anterior and posterior approaches may be optional in selected cases of dumbbell extension. Subtotal or partial resection of the tumor 
with acceptable decompression of the spinal cord is another practical choice in cases of high surgical risk other than malignant spinal NST.

\section{Conflicts of Interest Disclosure}

The authors report no conflict of interest concerning the materials or methods used in this study or the findings specified in this article. All authors who are members of The Japan Neurosurgical Society (JNS) have registered online Self-reported COI Disclosure Statement Forms through the website for JNS members.

\section{References}

1) McCormick PC, Post KD, Stein BM: Intradural extramedullary tumors in adults. Neurosurg Clin N Am 1: 591-608, 1990

2) Seppälä MT, Haltia MJ, Sankila RJ, Jääskeläinen JE, Heiskanen O: Long-term outcome after removal of spinal neurofibroma. J Neurosurg 82: 572-577, 1995

3) Seppälä MT, Haltia MJ, Sankila RJ, Jääskeläinen JE, Heiskanen O: Long-term outcome after removal of spinal schwannoma: a clinicopathological study of 187 cases. J Neurosurg 83: 621-626, 1995

4) Kim P, Ebersold MJ, Onofrio BM, Quast LM: Surgery of spinal nerve schwannoma. Risk of neurological deficit after resection of involved root. J Neurosurg 71: 810-814, 1989

5) Miura $T$, Nakamura $K$, Tanaka H, Kawaguchi H, Takeshita K, Kurokawa T: Resection of cervical spinal neurinoma including affected nerve root: recovery of neurological deficit in 15 cases. Acta Orthop Scand 69: 280-282, 1998

6) McCormick PC, Torres R, Post KD, Stein BM: Intramedullary ependymoma of the spinal cord. $J$ Neurosurg 72: 523-532, 1990

7) Takami T, Yamagata T, Mitsuhashi Y, Hayasaki K, Ohata K: Direct surgery for spinal arteriovenous fistulas of the filum terminale with intraoperative image guidance. Spine 37: E1524-1528, 2012

8) Takami T, Yamagata T, Ohata K: Posterolateral sulcus approach for spinal intramedullary tumor of lateral location: technical note. Neurol Med Chir (Tokyo) 53: 920-927, 2013

9) Takami T, Yamagata T, Chokyu I, Ikeda H, Tsuyuguchi N, Ohata K: Surgery of spinal nerve sheath tumors originating from $\mathrm{C} 1$ or $\mathrm{C} 2$ of high cervical spine. Neurol Med Chir (Tokyo) 50: 1044-1049, 2010

10) Safavi-Abbasi S, Senoglu M, Theodore N, Workman RK, Gharabaghi A, Feiz-Erfan I, Spetzler RF, Sonntag VK: Microsurgical management of spinal schwan- nomas: evaluation of 128 cases. J Neurosurg Spine 9: $40-47,2008$

11) Nakamura $M$, Iwanami A, Tsuji O, Hosogane $N$, Watanabe K, Tsuji T, Ishii K, Toyama Y, Chiba $\mathrm{K}$, Matsumoto M: Long-term surgical outcomes of cervical dumbbell neurinomas. J Orthop Sci 18: 8-13, 2013

12) Hasegawa M, Fujisawa H, Hayashi $Y$, Tachibana $O$, Kida S, Yamashita J: Surgical pathology of spinal schwannoma: has the nerve of its origin been preserved or already degenerated during tumor growth? Clin Neuropathol 24: 19-25, 2005

13) Kaneko K, Kato Y, Kojima T, Imajyo Y, Taguchi $\mathrm{T}$ : Intraoperative electrophysiologic studies on the functions of nerve roots involved in cervical dumbbell-shaped schwannoma and their clinical utility. J Spinal Disord Tech 19: 571-576, 2006

14) Schultheiss R, Gullotta G: Resection of relevant nerve roots in surgery of spinal neurinomas without persisting neurological deficit. Acta Neurochir (Wien) 122: 91-96, 1993

15) Lot G, George B: Cervical neuromas with extradural components: surgical management in a series of 57 patients. Neurosurgery 41: 813-820; discussion 820-822, 1997

16) Celli P: Treatment of relevant nerve roots involved in nerve sheath tumors: removal or preservation? Neurosurgery 51: 684-692; discussion 692, 2002

17) Hakuba A, Komiyama M, Tsujimoto T, Ahn MS, Nishimura S, Ohta T, Kitano H: Transuncodiscal approach to dumbbell tumors of the cervical spinal canal. J Neurosurg 61: 1100-1106, 1984

18) Iwai Y, Hakuba A, Kanai M: Giant cervical dumbbellshaped neurinoma treated by transuncodiscal approach. Surg Neurol 40: 504-507, 1993

19) McCormick PC: Surgical management of dumbbell tumors of the cervical spine. Neurosurgery 38: 294-300, 1996

20) Zhao B, Xu J: Extensive posterolateral exposure and total removal of the giant extraforaminal dumbbell tumors of cervical spine: surgical technique in a series of 16 patients. Spine J 9: 822-829, 2009

21) Jiang L, Lv Y, Liu XG, Ma QJ, Wei F, Dang GT, Liu ZJ: Results of surgical treatment of cervical dumbbell tumors: surgical approach and development of an anatomic classification system. Spine 34: 1307-1314, 2009

Address reprint requests to: Toshihiro Takami, MD, Department of Neurosurgery, Osaka City University Graduate School of Medicine, 1-4-3 Asahi-machi, Abeno-ku, Osaka, Osaka 545-8585, Japan. e-mail: ttakami@med.osaka-cu.ac.jp 